\title{
The Machinability of Steels by Abrasive Water Jet
}

\author{
S. Rammohan, S. Thirumalai Kumaran, M. Uthayakumar
}

\begin{abstract}
Abrasive Water jet machining (AWJM) is a Non-Traditional manufacturing process, were the material is expelled from the workpiece by effect erosion of pressurized high-speed water stream mixed with high-speed abrasives. There are such a significant number of procedure parameters influence with nature of the machined surface can be done by AWJM. The process variables are, the cross speed, water driven weight, remain off separation, rough stream rate and kind of grating are significant. This measures in AWJM are Surface Roughness (SR, Rate of Material Removal (RMR), Kerf angle, cutting depth. At the past, the survive completed from different kinds of steel was inproved and investigated on $A W J M$ research by identifying with execution estimates checking and procedure control and process factor advancement. In this paper, a study undergoes on AWJM about feature pattern regarding various types of steels.
\end{abstract}

Keywords: AWJM, Process parameter, Process optimization, Monitoring, Control.

\section{INTRODUCTION}

$T_{\text {he }}$ manufacturing industry is ending up additional time quality situated with the headway in the worldwide economy. It ends up to utilize the machining procedures. For example, Chemical Machining, Laser Machining, Electric Discharge Machining, Abrasive Water jet machining, etc. Abrasive water jet machining (AWJM) is known as coarse water jet device (CWJD) strategy to use high-pressure water for conveying fast fly, entrained with coarse particles for a wide variety of materials stretching out from fragile to hard. AWJM has a versatile machining process mainly used to machine materials reaching out from sensitive to hard like titanium, Inconel, etc hard and difficult to machine materials.

Coarse water jet machining as shown in Fig. 1. The first mechanical suite produced by McCartney fabricating organization and introduced on Alto Boxboard in the year 1972. This system is fundamentally reasonable for gentle, weak and tough materials. This procedure works without warm creation, hence it was machined the surface free from Warmth influenced zone (WIZ) with remaining stresses. AWJM has higher machining flexibility and better

Revised Manuscript Received on December 30, 2019.

* Correspondence Author

S. Rammohan*, Department of Automobile Engineering, Kalasalingam Academy of Research and Education, Krishnankoil-626126, India. Email: rammohanmfg@gmail.com

S. Thirumalai Kumaran, Faculty of Mechanical Engineering, Kalasalingam Academy of Research and Education, Krishnankoil-626126, India. Email: thirumalaikumaran@yahoo.com

M. Uthayakumar, Faculty of Mechanical Engineering, Kalasalingam Academy of Research and Education, Krishnankoil-626126, India. Email: uthaykumar@gmail.com adaptability. The significant disadvantage on the procedure was to produces the noisy clamor and a muddled workplace. CWJD has several benefits for machining such as a) Quicker set-up and programming, b) Less delicate to material properties as it doesn't cause prattle, c) Very small attachment for utmost parts, d) Machine essentially for 2D structure on any material, e) No Heat Affect Zone (HAZ) on part, f) Machine wide plates

CWJD is regularly utilized for applications like metals, non-metals, composite materials, conducting and non conducting materials and its Covers etc. The AWJM can also be done using the exotic materials. The issues of high multifaceted nature fit as a fiddle, size, interest for item exactness, and surface completion can be illuminated through CWJD.

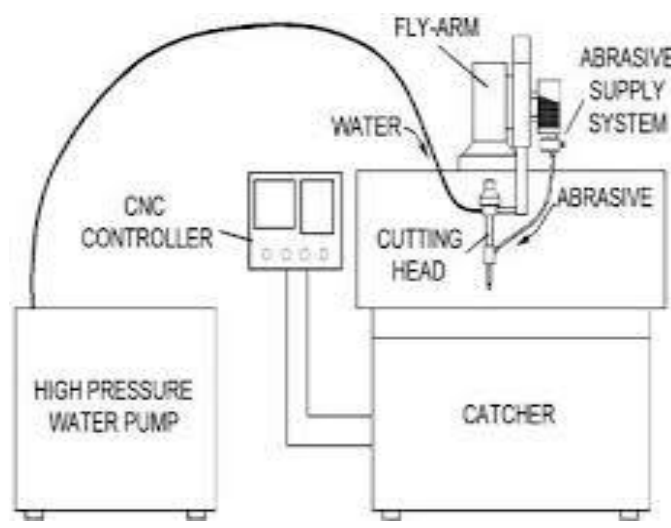

Fig. 1: Abrasive Water Jet Machine Set up

Coarse Water Jet Device (CWJD) has several approaches such as sports, medicinal, careful, instruments, optical, including car R\&D zones and hard material segments. The purpose of CWJD is to be machining of hard materials such as warmth treated instrument steels, titanium, composites, super combinations, earthenware production, and carbides. Additionally, it will be utilized to bite the dust and shape making ventures, aviation, aviation, and atomic businesses.

\section{LITERATURE REVIEW}

Sidda Reddy et al., [1] found that the present examination has enhanced machining variables utilized in CWJD of Inconel $800 \mathrm{H}$ utilizing the Taguchi technique. Transverse Speed (S) assumes a noteworthy job on impacting Rate of Material Removal (RMR) by $60 \%$ in the ANOVA F test. At that point, the real commitment to RMR is grating Flow Rate which is about $30 \%$. It was additionally found that Standoff distance is subcritical on affecting RMR. The affirmation trials have directed utilizing the ideal blend of the machining 


\section{The machinability of steels by abrasive water jet}

variables acquired from the Taguchi investigation. It is suggest to invariable blend for ideal material expulsion rate is $\mathrm{S} 3 \mathrm{R} 3 \mathrm{H} 3$ and the ideal reaction estimation of RMR is 5.87 grams/min.

If it should arise an occurrence of surface Roughness Standoff separation and transverse speed played real noteworthiness of about $47 \%$ and $37 \%$ separately. Rough stream rate having sub criticalness impact on SR. The affirmation examinations are found on Surface Roughness with S3R1H1 levels was obtained from Taguchi investigation.

Sandor RAVAI-NAGY et al., [2] examined two kinds of steel S235JR and S355JO cut with (CWJD) to find the surface unpleasantness - Bystronic ByJet Pro L, fluctuating the transverse speed and rough stream rate parameters. For S355JO steel the estimations of surface unpleasantness are lower than S235JR steel. This is on the grounds that the substance synthesis compound structure of the two sheets of steel is unique. At the point when the transverse speed is at specified value in estimations of surface, surface roughness is cause to decrease. At the point when the grating stream rate is greater, the estimations of surface roughness cause to decrease. Along these lines, the estimations of surface roughness are legitimately corresponding with the grating stream rate and conversely relative with the transverse speed. The estimations of surface roughness are lower for navigate line 1 area and increment when the estimations are made for cross-line 2. The qualities are the greatest when the estimations are made to transverse line 3 . This is on the grounds that the vitality of the rough water fly abatements with expanding the cutting profundity.

Arvind Kumar et al., [3] investigation demonstrates the constant impact in CWJD of Inconel 718 material. A joined RSM-BBD approach to improve the nature of the surface. In the process, the quadratic models for surface roughness have been defined as water force, AFR, SOD and transverse rate amid machining of Inconel 718 material with CWJD. It was discovered that cross rate and CFR is the major significant variables when SOD has small effect with superficially quality. It was observed that strain to be inconsequential among four parameters, however it has a critical collaboration impact superficially roughness. SEM investigation affirmed that even surface roughness was obtained with least SOD and with traverse rate at average AFR.

Sanghani et al., [4] explored the impact of different procedure parameters on kerf decreases, surface roughness and power utilization which are significant execution measures in CWJD. This investigation was carried out by fluctuating these parameters for cutting AISI 304 austenitic hardened steel utilizing an abrasive waterjet machining process. The impacts of water force, transverse speed, standoff height and grating stream rate on kerf decrease, surface roughness, and power utilization were examined. The kerf decreases and surface unpleasantness was extensive while control utilization was diminish with increment in transverse speed, SOD and RMR are decrease in water pressure.

Sreenivasa Rao et al., [5] investigated the impact of contrasting variables like water force, transverse rate, and standoff height on surface unpleasantness in CWJD of mild steel. Investigation of variance (ANOVA), F-test and SN Ratios are utilized to make the accompanying determinations. Cross Speed (S) is the majority critical feature in SR amid CWJD. In the meantime, water pressure and Standoff distance are sub noteworthy in impacting. The prescribed constant mix from ideal surface roughness is $\mathrm{P}$ (35000), S (80), and D (2.5).

Veselko Mutavgjic et al., [6] done the trial examination on hardened steel (EN 10088-3), Aluminum (EN AW-5083) is to direct research on the machining parameters sway on surface roughness of the machined parts and determines the end alluding to the way wherein certain machining parameters influence surface roughness. The objective of the paper was to dissect the effect of a few machining parameters on surface roughness and increase in the grating stream rate. Similarly, increment in water weight, give improved aftereffects of surface unpleasantness. The surface unpleasantness of machining increments when transverse speed increments.

Piotr Löschner et al., [7] investigated and exhibits the impact of cutting the rate on surface unpleasantness in CWJD of $10 \mathrm{~mm}$ thick stainless steel tests. Sample of cut surfaces was taken as image and they estimated roughness parameters in various areas crosswise over the profundity of cut. Where the abatement in cutting rate, cut surface condition enhance, which is atmost distinctive detectable for the lower some portion of inspected cut surfaces. It describes the cut surfaces by the event of two regions. In the main region, there are no distinctive machining traces and in next region machining imprints are effectively watched. The wide of the second region and the probability of fabricating imprints was firmly identified with the cutting rate.

Yuvaraj Natarajan et al., [8] examined the coarse water jet device (CWJD) directed cutting trial on D2 steel by various stream impingement points and grating cross-section sizes. The test information is factually dissected using the Simos-grey relation approach and the ANOVA trial. The grating particles can hold their vitality, which causes them to enter all the profoundly in the D2 steel. No analytical variation on the hardness of the CWJD D2 kerf divider cut surfaces at ideal and cutting state are analysed. They created a twisting impact through furrowing under beginning cutting conditions. In the surface geography and component examination, less numeral of peak and gap, and less infect was observed under ideal CWJD cutting condition.

Azhari et al., [9] explored a consolidated impact of waterjet striking and smoothing on the outside of austenitic tempered steel 304. The investigation of surface completion and the adjustment in rigidity were assessed. The surface morphology of serve examples with diminishing vitality of water beads has demonstrated a generally lower measure of pinnacle territories along the lines showing a smoother surface. Additionally, the pinnacle regions and the normal of the pinnacle statures were consistently decreased with different strides of waterjet treatment. The consolidated activity of surface solidifying and smoothing utilizing different strides in the waterjet experiment is helpful in decreasing the unpleasantness of the surface while keeping up/expanding its unpleasantness which may improve the exhaustion life of the part. Munuswamy Naresh Babu et al., [10] a coarse

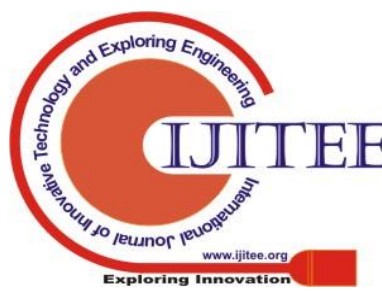


water jet device is a mechanical root whimsical cutting procedure that employs a blend of coarse and forced water as a middle of the surface to cut the material. This examination centers on dissecting the impact procedure variables like rate superficially harshness and kerf-point of AISI 1018 mild steel tentatively.

The investigations under Taguchi's L27 symmetrical cluster expansion, machined surfaces are additionally exposed to the examining electron magnifying lens (SEM) and nuclear power magnifying lens (AFM) for a point by point on the surface created. The Feed rate is the huge variable to oversee the reactions on surface roughness and kerf-edge. The reduce in feed rate decreases the surface unpleasantness esteem and kerf-edge as contrasted and the underlying settings.

Vlatko Marusic et al., [11] have done an investigation on cutting of AISI 304 by CWJD. In this work, the research impact of machining parameters on the stream slacking. For example, cut front geometry. They quantified the fly slacking at ten observing focuses by the profundity of cut. Further examination, it was observed that the expansion of working weight and rough stream rate causes a lessening in the water fly slacking. At long last, it proposes a firm connection between the water fly slacking and the eluded machining parameters. While an expansion in flyweight stream slacking likewise increments. It is recommended that whole length of the slice couldn't be machined with such machined parameters. Hence, it concludes the tests on similar material with various thickness.

Escobar-Palafox et al., [12] investigated, Inconel 718 by using the CWJD procedure for creating 3D highlights i.e, pockets. Using the measurable examination to create scientific models it incorporates all procedure variable communications and quadratic terms. A similar profundity of cut is delivered by using two distinctive weight settings (low level and a high level) with the fix every single other parameter. In this examination, they discovered undercut toward the start of the device way of the trial tests. The principal factor for controlling the undercut is the water weight, which has held in quadratic conduct. The undercut abatements with diminishing spout distance across and it shows the model reach out to incorporate extra basic quality characteristics. For example, surface unpleasantness of the base of the examples, microstructural highlights. At last, it was closes the advantage of examination for various basic procedure parameters, rough sort, grating coarseness, and apparatus ways.

Puneet Trivedi et al., [13]. they make a trial on cutting of austenite steel [AISI 316L] by CWJD. In this examination it varies three variables, namely water force, traverse speed and stand-off height on the surface quality of austenite steel (AISI $316 \mathrm{~L}$ ) are explored. It was observed that the significance of parameters are examined by ANOVA technique. The author concludes the list of experimental work is listed below: (a) Transverse rate is the major important variable to develop the surface roughness. (b) Surface roughness changes correlative to Transverse rate. (c) While enlarging in water force within the choose ambit upgraded the surface finish. (d) The effect of SOD on surface unpleasantness is minimum outstanding. The minimum surface unpleasantness point is noticed at average point of SOD. (e) Stretchmark effect is productive at of feed, water Force, standoff height, and flow rate of Coarse

higher point of SOD and Transverse rate. Uncut area (small nib) is notified when the Transverse rate is high.

Chithirai Pon Selvan et al., [14] describes the surveys the impact of procedure variable on the profundity of cut, which is a significant cutting presentation measure in grating waterjet cutting off stainless steel. The impacts of weight, grating mass stream rate, cross speed and Stand-off height contemplated was separated on the profundity of cut. From the trial results, it was created an observational specimen for the expectation of profundity of cut in the CWJD procedure of stainless steel using a relapse investigation. The created model is at last tested using the test information and observed to have the option to give sufficient forecasts inside the test range considered in this investigation

\section{SUMMARY}

Such a large number of examinations was done on the CWJD procedure. Investigation of procedure variable are, Coarse flow rate, transverse speed, standoff height, water force, Coarse size, hole width, and execution measures as Surface unpleasantness (SR), rate of material removal (RMR), kerf width, Profundity of cut (POC) was completed more by specialists. From the literature survey, it is observed that generally blends of procedure input Variable and output variables are analysed. The effect of output response is shown in Table 1.

\section{TABLE 1: EFFECT OF OUTPUT RESPONSES ON PROCESS} PARAMETERS

\begin{tabular}{|c|c|c|c|c|c|}
\hline \multicolumn{2}{|c|}{ Output responses $\rightarrow$} & \multirow{2}{*}{$\begin{array}{c}\text { Material } \\
\text { Removal } \\
\text { Rate }\end{array}$} & \multirow{2}{*}{$\begin{array}{c}\text { Surface } \\
\text { Roughness }\end{array}$} & \multirow{2}{*}{$\begin{array}{l}\text { Depth } \\
\text { of Cut }\end{array}$} & \multirow{2}{*}{$\begin{array}{c}\text { Kerf } \\
\text { Width }\end{array}$} \\
\hline Process & ameters & & & & \\
\hline \multirow[t]{2}{*}{$\begin{array}{c}\text { Water } \\
\text { Pressure }\end{array}$} & Increase & $\uparrow$ & $\begin{array}{c}\uparrow \text { at certain } \\
\text { extend }\end{array}$ & $\uparrow$ & $\uparrow$ \\
\hline & Decrease & & & & \\
\hline \multirow{2}{*}{$\begin{array}{c}\text { Traverse } \\
\text { Speed }\end{array}$} & Increase & $\uparrow$ & $\uparrow$ & & \\
\hline & Decrease & & & $\downarrow$ & \\
\hline \multirow{2}{*}{$\begin{array}{c}\text { Abrasive } \\
\text { Flow Rate }\end{array}$} & Increase & $\uparrow$ & & $\uparrow$ & \\
\hline & Decrease & & $\downarrow$ & & \\
\hline \multirow[t]{2}{*}{$\begin{array}{l}\text { Stand of } \\
\text { Distance }\end{array}$} & Increase & & $\begin{array}{l}\uparrow \text { at certain } \\
\text { extend }\end{array}$ & & \\
\hline & Decrease & & & & \\
\hline \multirow{2}{*}{$\begin{array}{c}\text { Work Feed } \\
\text { Rate }\end{array}$} & Increase & $\uparrow$ & & & \\
\hline & Decrease & & & & \\
\hline
\end{tabular}

( $\uparrow$ Increase $(\downarrow)$ Decrease

RMR was improved by expanding the cross speed and material removal rate. However serious issues with expanding cross rate is that surface unpleasantness and kerf status are diminished. By increasing MRR, it may decline unpleasantness. It is imperative to locate the ideal order for procedure parameters to give a superior nature of cutting surface. It was discovered that numerous specialists have utilized diverse improvement strategies like Taguchi technique, Anova, Regression investigation to discover the ideal cutting condition for the AWJM task. Less work has been accounted on multi-target enhancement of the awjm process. thereby no work has been accounted for the impact of the spout and whole distance across. 


\section{ACKNOWLEDGMENT}

The authors submit their thanks to Combat Vehicles Research and Development Establishment (CVRDE), Avadi, Chennai for providing financial support to carry out this work (CVRDE/19CR0002/WKS/18-19/LT dated 10/8/18).

\section{REFERENCES}

1. D. S. Reddy, A. S. Kumar, and M. S. Rao, "Parametric Optimization of Abrasive Water Jet Machining of Inconel $800 \mathrm{H}$ Using Taguchi Methodology," Univers. J. Mech. Eng., vol. 2, no. 5, Dec. 2017, pp. $158-162$

2. Ravai-Nagy, Sandor, and Nicolae Medan. "Study of Surface Roughness for Steel Parts Cut with Abrasive Water Jets." Magazine of Hydraulics, Pneumatics, Tribology, Ecology, Sensorics, Mechatronics (HIDRAULICA) 4 (2016): 12-17.

3. A. Kumar, H. Singh, and V. Kumar, "Study the parametric effect of abrasive water jet machining on surface roughness of Inconel 718 using RSM-BBD techniques," Mater. Manuf. Process., vol. 33, no. 13, pp. 1483-1490, 2018.

4. C. R. Sanghani and M. M. Korat, "Performance Analysis of Abrasive Water Jet Machining Process for AISI 304 Stainless Steel," 2017.

5. M. S. Rao, "Parametric Optimization of Abrasive Waterjet Machining for Mild Steel: Taguchi Approach," Int. J. Curr. Eng. Technol., vol. 2, no. 2, 2014, pp. 28-30.

6. Mutavgjic, Veselko, et al. "Experimental investigation of surface roughness obtained by abrasive water jet machining." 15 th International Research/Expert Conference,"Trends in the Development of Machinery and Associated Technology”, Prague, Czech Republic.2011. No. 12.

7. P. Löschner, K. Jarosz, and P. Niesłony, "Investigation of the effect of cutting speed on surface quality in abrasive water jet cutting of $316 \mathrm{~L}$ stainless steel," in Procedia Engineering, vol. 149, pp. 276-282, 2016.

8. N. Yuvaraj and M. P. Kumar, "Investigation of process parameters influence in abrasive water jet cutting of D2 steel," Mater. Manuf. Process., vol. 32, no. 2, pp. 151-161, 2017.

9. Azhari, A., et al. "Influence of waterjet peening and smoothing on the material surface and properties of stainless steel 304." Surface and Coatings Technology 258 (2014): 1176-1182.

10. M. N. Babu and N. Muthukrishnan, "Exploration on Kerf-angle and Surface Roughness in Abrasive Waterjet Machining using Response Surface Method," J. Inst. Eng. Ser. C, vol. 99, no. 6, pp. 645-656, 2018

11. Marušić, Vlatko, et al. "Effect of machining parameters on jet lagging in abrasive water jet cutting." Tehnički vjesnik 20.4 (2013): 677-682.

12. G. A. Escobar-Palafox, R. S. Gault, and K. Ridgway, "Characterisation of abrasive water-jet process for pocket milling in Inconel 718," Procedia CIRP, vol. 1, no. 1, pp. 404-408, 2012.

13. P. Trivedi, A. Dhanawade, and S. Kumar, "An experimental investigation on cutting performance of abrasive water jet machining of austenite steel (AISI 316L)," Adv. Mater. Process. Technol., vol. 1, no. 3-4, pp. 263-274, 2016.

14. M. C. P. Selvan et al., "Assessment of Process Parameters in Abrasive Waterjet Cutting of Granite," Front. Mech. Eng., vol. 1, no. 3, pp. 929-933, 2012.

\section{AUTHORS PROFILE}
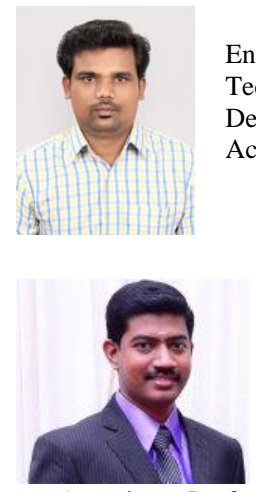

S. Thirumalai Kumaran completed his Ph.D. degree in Mechanical Engineering from Kalasalingam Academy of Research and Education (KARE), India, in 2015. After completing Ph.D., he worked as an Assistant Professor at School of Mechanical Engineering, Yeungnam University, South Korea for a period of one year. He is currently an Associate Professor at School of Automotive and Mechanical Engineering, KARE.

S. Rammohan completed his M.E., Manufacturing Engineering from Kamaraj College of Engineering and The currently, he is a research scholar in the Department of Automobile Engineering, Kalasalingam Academy of Research and Education.

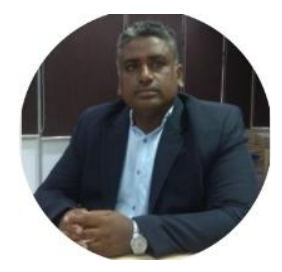

M. Uthayakumar completed his Doctoral work in the area of Precision Machining. He is actively working in the development of high strength light weight composites. His other areas of interest include processing of metal matrix, polymer matrix, ceramic matrix composite and its performance studies. 